\title{
Anti-Proliferative Activity of Triterpenes Isolated from Clinicanthus nutans on Hep-G2 Liver Cancer Cells
}

\author{
Khairun Najwa Zakaria ${ }^{1}$, Azura Amid ${ }^{2 *}$, Zubaidah Zakaria ${ }^{3}$, Parveen Jamal, \\ Azli Ismail ${ }^{3}$
}

\begin{abstract}
Problem statement: Clinicanthus nutans has been used by Malaysian since long time ago. It is used to treat many diseases including cancer. Many studies carried out on its crude extract but no clear report on the specific secondary metabolites responsible for its nature in treating selected diseases. Objective: This study aims to confirm the practice carried out by many people on the usage of Clinicanthus nutans in treating cancer. Methods: C. nutans leaves were extracted by methanol. Thin layer chromatography was used to identify the suitable solvent for fractions separation. The fractions were then separated at larger volume using gravity column chromatography. Each fraction was tested on its anti-proliferative activity on Hep-G2 liver cancer cells by MTT assay. The phytochemical screening was carried out to identify the bioactive compound based on qualitative analysis. Results: The fraction 2 (F2) of C. nutans showed the lowest $\mathrm{IC}_{50}$ value of $1.73 \mu \mathrm{g} / \mathrm{ml}$ against Hep-G2 cancer cells, and it is identified as triterpenes. Conclusion: The fraction F2 identified as triterpenes isolated from $C$. nutans has potential as an anti-proliferative agent against liver cancer.
\end{abstract}

Keywords: Clinicanthus nutans- anti-proliferative- triterpenes- liver cancer

Asian Pac J Cancer Prev, 20 (2), 563-567

\section{Introduction}

Clinacanthus nutans (C. nutans) Lindau, or commonly known as Sabah Snake Grass or Belalai Gajah in Malay is one of the plants that is known for its high medicinal values. C. nutans belongs to the family of Acanthaceae. It is a small shrub, native in tropical weather and can be found easily in Malaysia, Thailand, and Indonesia (Alam et al., 2016). It is normally consumed by Malaysian especially the Chinese ethnic because they believed it might prevent them from cancer. Interestingly, few scientific studies were carried out to confirm these.

Arullapan et al., (2014) conducted a study to evaluate the in vitro cytotoxic, antioxidant and antimicrobial activities of $C$. nutans leave extracts and its semi-fractions. In that study, HeLa (cervical cancer) and K-562 (leukemia) cell lines were used. The crude extract of $C$. nutans leaves $(0.2$ to $10 \mu \mathrm{g} / \mathrm{mL})$ was tested against HeLa and K-562 cell lines using 3-(4,5-dimethylthiazol-2-yl)2,5-diphenyltetrazolium bromide (MTT) assay, and antioxidant activity using 1,1-diphenyl-2-picrylhydrazyl (DPPH) assay. The results showed that the fractions isolated from ethyl acetate leaf extract demonstrated cytotoxic, antioxidant and antimicrobial activities. The $\mathrm{IC}_{50}$ values against $\mathrm{HeLa}$ and $\mathrm{K}-562$ cell lines during cytotoxicity assay were 18.0 and $20.0 \mu \mathrm{g} / \mathrm{mL}$, respectively. However, there is no study reported liver cancer treated with $C$. nutans extract.

The Hep-G2 cell line was originally established in 1979 by Barbara Knowles and colleagues (López-Terrada et al., 2009). Hep-G2 liver cancer cell line was derived from 15 years old Caucasian American white male, whose well-differentiated Hepatocellular carcinoma, the most common type of liver cancer (ATCC, 2003). Hep-G2 is adherent, epithelial-like cells growing as monolayers and in small aggregates. These cells are epithelial in morphology, have a modal chromosome number of 55, and are not tumorigenic in nude mice (ATCC, 2003). Because of their high degree of morphological and functional differentiation in vitro, Hep-G2 cells are a suitable model to study human liver diseases (Mersch-Sundermann et al., 2004).

\section{Materials and Methods}

\section{Raw Material}

The leaves of $C$. nutans were used for this project. The C. nutans leaves were harvested from the self-plant garden in Nilai, Negeri Sembilan, Malaysia. A plant sample deposited in the herbarium at the Kulliyyah of Architecture 
and Environmental Design (KAED), International Islamic University Malaysia with voucher number KAED/HBL/ S1A047/2018/706. The name of the plant was checked on www.theplantlist.org

\section{Cell Line}

This study used Hep-G2 liver cancer cell line (originally from ATCC No: HB-8065; obtained from Institute Medical Research, Kuala Lumpur) as the experimental cancer cells. It was kept in liquid nitrogen until further use.

\section{Chemicals and Reagents}

All the chemicals and reagents used in this project are laboratory grade. They were purchased from Merck (USA), Sigma-Aldrich (USA), GIBCO (USA) and Fisher Scientific (USA).

\section{C. nutans Extraction and Fractionation}

The freshly harvested of $C$. nutans leaves were air dried for $72 \mathrm{~h}$. The dried leaves were grounded into a fine powder to increase the surface area. The $C$. nutans extract $(25 \mathrm{~g})$ was then prepared using the maceration process with methanol $(250 \mathrm{~mL})$ for $72 \mathrm{~h}$ at room temperature under constant shaking. The extract collected was wrapped with aluminum foil, to keep them in the less-light exposure condition and stored at $4{ }^{\circ} \mathrm{C}$ chiller until use (P'ng et al., 2013). The C. nutans extract was separated by thin layer chromatography (TLC) and next by column chromatography. TLC plates $(20 \times 10 \mathrm{~cm})$ coated with silica gel (Merck, Germany) and ultraviolet (UV) lamp for spot detection was used in this experiment. Samples $(20 \mu \mathrm{L})$ were spotted on TLC plates using a syringe, two centimeter above the bottom edge and allow to develop using mobile phase until it reached the solvent front. The plates were then removed, dried, observed under the UV light and finally, the RF-values were calculated. Best separations were achieved with hexane: ethyl acetate (7:3). Column chromatography was performed using the identified mobile phase to get more volume of each fraction.

\section{Anti-proliferative Test}

The Hep-G2 cells were cultured in DMEM supplemented with $1 \%$ antibiotics $(100 \mathrm{U} / \mathrm{mL}$ penicillin, $100 \mu \mathrm{g} / \mathrm{mL}$ streptomycin) and $10 \%$ Fetal Bovine Serum (FBS) and incubated at $37^{\circ} \mathrm{C}$ in a $95 \%$ air and $5 \%$ $\mathrm{CO}_{2}$ atmosphere. Once confluence, Hep-G2 cells were trypsinised, re-suspended in media and counted using a haemocytometer. The cells were then diluted to $1.0 \times 10^{5}$ cell $/ \mathrm{mL}$ and plated in $100 \mathrm{~mL}$ of medium/well in 96-well plate. The cells were then incubated for $24 \mathrm{~h}$. After $24 \mathrm{~h}$, media was removed and the cells were then exposed to the four $C$. nutans leaves extract active fractions in the presence of various concentrations at eight concentration intervals (between 0.78 and $100 \mu \mathrm{g} / \mathrm{mL}$ ) for another $24 \mathrm{~h}$ at $37^{\circ} \mathrm{C}$. The sample solutions were then removed and washed with phosphate buffer solution ( $\mathrm{pH}$ 7.4). A volume of 20 $\mu \mathrm{L} /$ well of MTT at $5 \mathrm{mg} / \mathrm{mL}$ concentration was added to each well. The assay then was incubated for $4 \mathrm{~h}$ at $37^{\circ} \mathrm{C}$. The amount of formazan was determined by measuring the absorbance at $570 \mathrm{~nm}$. The higher the absorbance value, the more converted formazan is present, and so the higher the number of viable cells. This method was carried out in triplicates. The data obtained using microplate reader (ThermoFisher) was used to calculate the percentage of viable and unviable cells. The formulas used (Wan Chik et al., 2010) were in equations (1) and (2) below.

$$
\% \text { cell growth }=\frac{O D \text { sample }}{O D \text { control }} \times 100 \quad \text { Equation } 1
$$

$$
\% \text { Cell killed }=100-\% \text { cells growth } \quad \text { Equation } 2
$$

Where the value of the optical density (OD) sample is the OD for the cells treated with active fractions and the OD control is the OD for cells without treatment.

\section{Phytochemical Screening}

Phenol was detected using Ferric Chloride test (Ahluwalia and Raghav, 1997). Flavonoids were detected using Alkaline Reagent test (Evans, 2002), and Ammonia test (Harborne, 1998). Alkaloids were detected by Wagner's test (Harborne, 1998). Saponins were detected by Sulphuric Acid Reaction test and Emulsion Formation test (Brain and Turner, 1975). Terpenoids were detected by Salkowski test (Ayoola et al., 2008) and Liebermann-Burchard test (Kumar et al., 2010). Fixed oils and fats were detected by oil stain test (Kokate et al., 2008) and finally, Cardiac Glycosides was detected by Keller Killiani test (Ayoola et al., 2008).

\section{Results}

\section{C. nutans Extraction and Fractionation}

Table 1 presents the results for extraction and fractionation. The hexane/ethyl acetate at a ratio of 7:3 resulted in four separate spots on the TLC plate. For further separation by open column chromatography, ratio $7: 3$ has been chosen as mobile phase due to the suitable RF-value showing well-separated spots with RF-value from 0.34 to 0.93 , polarity index of 1.86 suggested that there is a preeminent separation of the C. nutans extract. This is because it would be easier to collect the fractions during the open column chromatography analysis when the spots are not close to each other.

For column chromatography, separated fractions were collected in $15 \mathrm{~mL}$ centrifuge tubes and were labeled with number 1 to 77 and proceed to vacuum concentrator. Again, TLC was used to monitor the effectiveness of the separation. Fractions with similar RF-value were group together. In this case, based on the RF-value, tube number 1 to 6 were group together and named as compound/ fraction $1(\mathrm{~F} 1)(\mathrm{RF}-\mathrm{value}=0.93)$, tube number 19-29 were fraction $2(\mathrm{~F} 2)(\mathrm{RF}-\mathrm{value}=0.83)$, tube number $40-46$ were fraction $3(\mathrm{~F} 3)(\mathrm{RF}-\mathrm{value}=0.59)$ and tube number $70-77$ were fraction $4(\mathrm{~F} 4)(\mathrm{RF}$-value $=0.34)$. At this point, the four spots showed different RF-values because they might represent different compound, which at the same time having different polarity. Thus, phytochemical screening process takes part for further validation. 
Table 1. Rf value with Different Solvents Ratio for Hexane/ethyl Acetate

\begin{tabular}{lccc}
\hline $\begin{array}{l}\text { M2 solvent } \\
\text { ratio }\end{array}$ & $\begin{array}{c}\text { No. of } \\
\text { spots } \\
\text { detected }\end{array}$ & $\begin{array}{c}\text { Polarity index } \\
\text { of mixture } \\
\text { (PI mix) }\end{array}$ & $\begin{array}{c}\text { Retardation } \\
\text { factor } \\
\text { (Rf) value. }\end{array}$ \\
\hline 9:01 & 1 & 0.62 & 0.35 \\
$8: 02$ & 4 & 1.24 & 0.22 \\
& & & 0.39 \\
& & & 0.53 \\
$7: 03$ & 4 & 1.86 & 0.79 \\
& & & 0.34 \\
& & & 0.59 \\
& & & 0.83 \\
$1: 01$ & 0 & 3.1 & 0.93 \\
$3: 07$ & 0 & 4.34 & - \\
$2: 08$ & 0 & 4.96 & - \\
$1: 09$ & 0 & 5.58 & - \\
\hline
\end{tabular}

Phytochemical screening of C. nutans fractions

The compounds identified via phytochemical screening are tabulated in Table 2. They were evaluated based on colour formation, precipitate, froth formation, visibility of the ring formation between two layers and stain formation. The fractions revealed the presence of carotenoids (F1), triterpenes (F2), saponins (F4) and cardiac glycosides (F3) (Table 2) as secondary metabolites that might be responsible for the anti-proliferative activity of the cells. Phenols, flavonoids, alkaloids, fixed oils, and fats were not detected in the fractions.

\section{$I_{50}$ of C. nutans Fractions by MTT Assay}

This assay was carried out to identify the active fraction which has the anti-cancer activity and determine its $\mathrm{IC}_{50}$. In this experiment, Hep-G2 cells were treated with all four active fractions (F1 - F4) and taxol used as a standard at eight concentration intervals, ranging from

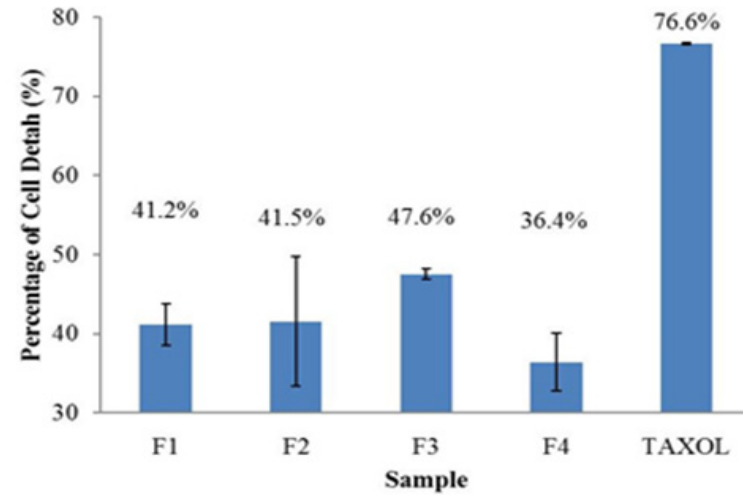

Figure 1. Percentage of Hep-G2 Cells Death after Treated with Isolated Fractions (F1-F4) from $C$. nutans Leaves Extract $(1.56 \mu \mathrm{g} / \mathrm{mL})$, and Taxol $(2 \mu \mathrm{g} / \mathrm{ml})$ Presented with the Standard Deviation Obtained from Three Independent Experiments

0.781 to $100 \mu \mathrm{g} / \mathrm{mL}$ and 0.0156 to $2 \mu \mathrm{g} / \mathrm{mL}$, respectively. The active fraction that is capable of inhibiting the cells growth can be assumed to be useful in the treatment of liver cancer.

For screening purpose, the percentage of cell death of all active fractions were plotted in a bar graph at the same concentration $(1.56 \mu \mathrm{g} / \mathrm{mL})$, and taxol at $2 \mu \mathrm{g} / \mathrm{mL}$. Referring to Figure 1, among all those four fractions at concentration $1.56 \mu \mathrm{g} / \mathrm{mL}$, active fraction 3 (F3) which is also preliminarily identified as cardiac-glycosides (Table 2) demonstrated the highest percentage of Hep-G2 cell death with $47.6 \%$.

The data for the MTT assay were plotted in the graph of percentage of viable cells versus concentration $(\mu \mathrm{g} / \mathrm{mL})$ to identify the $\mathrm{IC}_{50}$ of each fraction and taxol. The result (Table 3 ) showed that $\mathrm{F} 2$ gave the lowest $\mathrm{IC}_{50}$ value (1.73 $\mu \mathrm{g} / \mathrm{ml}$ ), while $\mathrm{F} 3$ gave the $\mathrm{IC}_{50}$ of $4.51 \mu \mathrm{g} / \mathrm{ml}$. The results suggesting that F2 is more potent than F3. When treated with adherent Hep-G2 cells, taxol gave the $\mathrm{IC}_{50}$ value of $0.11 \mu \mathrm{g} / \mathrm{mL}$. Thus, active fraction F2 is considered to demonstrate a good result in this experiment.

Table 2. Phytochemical Evaluation of the Active Secondary Metabolites Presents in the Isolated Active Fractions $(\mathrm{F} 1-\mathrm{F} 4)$

\begin{tabular}{|c|c|c|c|c|c|c|}
\hline \multirow[t]{2}{*}{ Class of compound } & \multirow[t]{2}{*}{ Test } & \multirow[t]{2}{*}{ Specific constituents } & \multicolumn{4}{|c|}{ Result } \\
\hline & & & $\mathrm{F} 1$ & $\mathrm{~F} 2$ & F3 & F4 \\
\hline \multirow[t]{3}{*}{ Phenolic compound } & Ferric chloride test & Phenols & - & - & - & - \\
\hline & Alkaline reagent test & Flavonoids & - & - & - & - \\
\hline & Ammonia test & Flavonoids & - & - & - & - \\
\hline Alkaloids & Wagner's test & Alkaloids & - & - & - & - \\
\hline \multirow[t]{6}{*}{ Terpenoids } & Emulsion formation test & Saponin & - & - & + & ++ \\
\hline & Liebermann-Burchard test & Triterpenes & - & + & - & - \\
\hline & Salkowski test & Triterpenes & - & + & - & - \\
\hline & Modifies Brontranger's test & Cardiac-glycosides & - & - & + & - \\
\hline & Legal's test & Cardiac-glycosides & - & - & + & - \\
\hline & Sulphuric acid test & Carotenoids & + & - & - & - \\
\hline Carbohydrates & & Carbohydrates & - & - & - & - \\
\hline Fixed oils and fats & Stain test & Oil and fats & - & - & - & - \\
\hline
\end{tabular}

Positive (+) and negative (-) signs showed the presence and absence of metabolites in the fractions, with (++) strong colour and $(+)$ mild colour. 
Table 3. the $\mathrm{IC}_{50}$ Value of Each Fraction and Taxol

\begin{tabular}{lccccc}
\hline Sample & F1 & F2 & F3 & F4 & Taxol \\
\hline $\mathrm{IC}_{50}(\mu \mathrm{g} / \mathrm{mL})$ & 4.68 & 1.73 & 4.51 & 10.5 & 0.11 \\
\hline
\end{tabular}

\section{Discussion}

RF-value is equal to the distance traveled by the substance divided by the distance traveled by the solvent. Typically, an effective solvent is one that gives RF- value in the range of 0.5-1.0 (Touchstone, 1992). It is also reported that the solvent system with the highest polarity will make the components in the mixture move along with the solvent and caused no separation observed and the RF-value will be too large. Thus, from the results in Table 1, the solvent system of hexane : ethyl acetate with ratio $7: 3$, polarity index value of 1.83 which gave the best readings of RF-values, ranging from 0.34 to $0.93 \mathrm{had}$ been selected for further use in column chromatography. Later, column chromatography (CC) was used to collect the active fractions from crude of $C$. nutans leaves extract by gravity force. CC applied the same principles as TLC but performed at larger volume (Chik et al., 2011; Tolar and Neglia, 2003). Subsequently, phytochemical screening of the collected four active fractions was carried out to preliminary identify the type of secondary metabolites separated and isolated by CC. According to Table 2, terpenoids were isolated and collected in this experiment. This finding was supported by (Wan Chik et al., 2010; Çitoğlu and Acıkara, 2012), because of ethanol, methanol, and water led to the extraction of highly oxygenated namely polar triterpenes as well as triterpenoid and sterol glycosides. Besides, Tsado et al., (2016) used the same method and successfully extracted terpenoids from Newbouldia laevis and Crateva adansonii leaves using methanol as a solvent. Secondly, based on the phytochemical screening result (Table 2) shows that the presence of carotenoid in F1, triterpenes in F2, saponin in F3 and cardiac glycosides in F4. Referring to (Yamunadevi et al., 2011; Harborne, 1998), the combination of hexane: ethyl acetate is commonly used as the mobile phase to isolate and purify terpenoids group. Yamunadevi and co-workers (Yamunadevi et al., 2011) reported that 27 different types of terpenoids were detected by HPLTC, with RF- value range of 0.31 to 0.97 . This information supports our current findings, which high possibility that the F2 is in terpenoids group.

The current study shows the interest of valuable natural substance, such as terpenoids has been increasing day by day (Yamunadevi et al., 2011). Terpenoids are defined as secondary metabolites with molecular structures containing carbon backbones made up of isoprene (2-methylbuta- 1, 3-diene) units (Harborne, 1998). More than 36000 terpenoids compounds have been identified, making terpenoids the largest class of plant metabolites. In particular, terpenoids contained in many herbal plants, with several kinds of terpenoids are already available for pharmaceutical applications today, such as taxol and artemisinin as a chemotherapy drug and malaria medicines, respectively (Yamunadevi et al., 2011). Generally, plant terpenoids are well-known to possess useful aromatic qualities (Harborne, 1998). It has been used traditionally in herbal remedies and still under investigation of the pharmaceutical function, such as antibacterial, anticancer and other therapeutic properties. Until now, there is no such study which carried out specifically on terpenoids isolated from $C$. nutans leaves extracted as an anticancer agent. However, the crude extract of this plant shows their anticancer properties. Fong (2015) reported that the methanol and water extracts of C. nutans leaves were cytotoxic against D24 and MM418C1 melanoma cells, MCF-7 and BT474 breast carcinoma cells. Other pharmacology properties of crude C. nutans leaves extract such as antioxidant activity, anti-proliferative activity, anti-tumour, and cytotoxic agents. This suggests that the extracts may contain the anti-cancer compound. Based on these results, terpenoids may be considered as a promising anticancer agent present in the $C$. nutans leaves extracts. The cytotoxicity of the fractions were further defined by determining the half maximal inhibitory concentration $\left(\mathrm{IC}_{50}\right)$. The four active fractions from $C$. nutans leave extract were used from this experiment onwards.

Initial yellow in colour of MTT assay is reduced to purple formazan in the mitochondria of living cells. The reduction will take place only when the mitochondrial reductase enzyme is active. Therefore, the conversion can be directly related to the number of viable/living cells. Through this experiment, the effectiveness of the sample in causing death to the cells can be measured by the amount of purple formazan produced after the sample treated with active fractions or taxol compared to the amounts of untreated cells (Freshney, 2010). Among all the four active fractions of $C$. nutans leaves extract, F3 showed the highest percentage of Hep-G2 cells death $(47.6 \%$ ) at $1.56 \mu \mathrm{g} / \mathrm{mL}$, while taxol gave $76.6 \%$ at concentration $2 \mu \mathrm{g} / \mathrm{mL}$. However, active fraction F2 exhibited the highest percentage of Hep-G2 cancer cells inhibition in almost every concentration tested (4 over 6 concentration tested; $1.56,3.13,6.25$ and $25 \mu \mathrm{g} / \mathrm{ml})$ than other active fractions.

Later, the MTT assay results on adherent Hep-G2 cells (Figure 1) shows that F2 gave a reasonable and exceptional effect against Hep-G2 liver cancer cells because the value of $\mathrm{F} 2 \mathrm{IC}_{50}$ is in the acceptable range of suitable as cytotoxicity agent. According to the US National Cancer Institute (NCI) plant screening program, plant extract is generally considered to have in vitro cytotoxicity activity if the $\mathrm{IC}_{50}$ value is less than $20 \mu \mathrm{g} /$ $\mathrm{mL}$ (Boik, 2001). The $\mathrm{F} 2$ fraction gave an $\mathrm{IC}_{50}$ value higher than taxol but still lesser than $20 \mu \mathrm{g} / \mathrm{mL}$, supporting a milder effect of native-based product compared to highly, toxic taxol. Several papers on C. nutans leaves extract showed that the crude extract possesses potential anticancer agents towards cultured cancer cell lines such as HeLa and K-562 cells (Arullappan et al., 2014) and Raji lymphoma cells (Yong et al., 2013) but those studies did not identify the type of secondary metabolites responsible for the anti-cancer activity. While, from a phytochemical screening test of this study, an isolated active fraction from crude $C$. nutans leaves extract, F2 showed positive results towards Lieberman-Burchard reagent, indicated 
that this compound possibly triterpenoid. Triterpenoid is a well-known secondary metabolite compound that possesses such anticancer properties. Triterpenoid derived from avocado showed a positive result on Hep-G2 liver cancer cells, suggesting the in vitro cytotoxicity of triterpenoid (Abubakar et al., 2017). The same study also reported that triterpenoid was also safe to normal Vero cells (Abubakar et al., 2017). Many triterpenoids have various biological activities, e.g., anti-tumour, anti-viral, antibacterial, virostatic, anti-ulcerogenic, anti-inflammatory (Dzubak et al., 2006). Triterpenoids are used for medicinal purposes in many Asian countries for anti-inflammatory, analgesic, antipyretic, hepatoprotective, cardiotonic, sedative and tonic effects (Moses et al., 2014). An increasing number of triterpenoids have been reported to exhibit cytotoxicity against a variety of in vitro cancer cells (MCF-7 breast cancer cells, Hep-G2 liver cancer cells) without manifesting any toxicity in normal cells (Vero cells) ( Moses et al., 2014).

In conclusion, the triterpenoids isolated from $C$. nutans were able to show the positive anti-proliferative effect on Hep-G2 liver cancer cells. Thus, C. nutans is a potential alternative or complementary medicine for treating liver cancer in a human.

\section{Acknowledgments}

The authors are grateful to the Department of Biotechnology Engineering, International Islamic University Malaysia, for providing the laboratory facilities to carry out the research. We are also thanking to Institute of Medical Research, Kuala Lumpur for providing the Hep-G2 liver cancer cell for this study.

\section{References}

Abubakar ANF, Achmadi SS, Suparto IH (2017). Triterpenoid of avocado (Persea americana) seed and its cytotoxic activity toward breast MCF-7 and liver HepG2 cancer cells. Asian Pac J Trop Biomed, https://doi.org/10.1016/j. apjtb.2017.01.010

Alam MNF, Bristi NJ, Rafiquzzaman M (2013). Review on in-vivo and in vitro methods evaluation of antioxidant activity. Saudi Pharm J, 21, 143-52.

Arullappan S, Rajamanickam P, Thevar N, Kodimani CC (2014). In vitro screening of cytotoxic, antimicrobial and antioxidant activities of Clinacanthus nutans (Acanthaceae) leaf extracts. Trop J Pharma Res, https://doi.org/10.4314/tjpr.v13i9.11.

Ayoola GA, Coker HAB, Adesegun SA, et al (2008). Phytochemical screening and antioxidant activities of some selected medicinal plants used for Malaria therapy in southwestern Nigeria. Trop J Pharm Res, https://doi. org/10.4314/tjpr.v7i3.14686.

Ahluwalia VK, Raghav S (1997). Comprehensive experimental chemistry. New Age International, pp 119.

Boik J (2001). Natural compounds in cancer therapy promising nontoxic antitumor agents from plants and other natural sources. Oregon Med Press, https://doi.org/10.1016/j. infsof.2008.09.005

Brain KR, Turner TO (1975). The practical evaluation of phytophamtaceuticals. Bristol:Wright-Scientecknica, pp 152.

Chik WDW, Amid A, Jamal P (2011). Predicting group of metabolites available in partially purified tomato leaves extract showing anticancer activity by high performance liquid chromatography (HPLC) and fourier transform infrared (FTIR). Afr J Biotechnol, 10, https://doi. org/10.5897/AJB11.2736.

Çitoğlu GS, Acıkara ÖB (2012). Column chromatography for terpenoids and flavonoids. (S. Dhanarasu, Ed.) (Chromatogr). Croatia: InTech, pp 13-51.

Dzubak P, Hajduch M, Vydra D, et al (2006). Pharmacological activities of natural triterpenoids and their therapeutic implications. Nat Prod Rep, 23, 394-411.

Evans WC, Trease GE: Trease and Evans pharmacognosy (2002). W.B. Saunders, China, pp 193-407.

Fong SY (2015). Genetic, phytochemical and bioactivity studies of Clinacanthus nutans (Burm. f.) Lindau (Acanthaceae). RMIT University.

Freshney RI (2010). Culture of Animal Cells: A Manual of Basic Technique and Specialized Application (6 th Edn.). Canada: John Wiley and Sons, Inc.

Harborne JB (1998). Phytochemical methods: A guide to modern techniques of plant analysis (3rd Edn.). New York, Chapman and Hall, pp 279.

Kokate CK, Purohit AP, Gokhale SB (2008). Pharmacognosy. (42 th Edn.). Hyderabad. Nirali Prakashan, pp 17.

Kumar U, Kumar B, Bhandari A, Kumar Y (2010). Phytochemical investigation and comparison of antimicrobial screening of Clove and Cardamom. Int J Pharma Sci Res, 1, 138-47.

López-Terrada D, Cheung SW, Finegold MJ, Knowles BB (2009). Hep G2 is a hepatoblastoma-derived cell line. Hum Pathol, https://doi.org/10.1016/j.humpath.2009.07.003

Mersch-Sundermann V, Knasmüller S, Wu XJ, Darroudi F, Kassie F (2004). Use of a human-derived liver cell line for the detection of cytoprotective, antigenotoxic and cogenotoxic agents. Toxicol In Vitro, https://doi. org/10.1016/j.tox.2004.02.009

Moses T, Papadopoulou KK, Osbourn A (2014). Metabolic and functional diversity of saponins, biosynthetic intermediates and semi-synthetic derivatives. Crit Rev Biochem Mol Biol, https://doi.org/10.3109/10409238.2014.953628

P'ng XW, Akowuah GA, Chin JH (2013). Evaluation of the sub-acute oral toxic effect of methanol extract of Clinacanthus nutans leaves in rats. $J$ Acute Dis, https://doi. org/10.1016/S2221-6189(13)60090-6

Tolar J, Neglia JP (2003). Column chromatography. The laboratory notebook introductory organic lab. JRSM, pp 39.

Touchstone JC (1992). Practice of thin layer chromatography (3 rd Edn.). New York: John Wiley-Interscience, pp 14.

Tsado NA, Lawal B, Kontagora GN, et al (2016). No Title. $J$ Adv Med Pharma Sci, 8, 1-7.

Wan Chik WD, Amid A, Jamal P (2010). Purification and cytotoxicity assay of tomato (Lycopersicon esculen turn) leaves methanol extract as potential anticancer agent. J Appl Sci, 10, pp 3285.

Whelan J (2002). Targeted taxane therapy for cancer. Drug Discov Today, https://doi.org/10.1016/S1359-6446(01)02149-3.

Yamunadevi M, Wesely EG, Johnson M (2011). Phytochemical studies on the terpenoids of medicinally important plant Aerva lanata L. Using HPTLC. Asian Pac J Trop Biomed, https://doi.org/10.1016/S2221-1691(11)60159-7.

Yong YK, Tan JJ, Teh SS, et al (2013). Clinacanthus nutans extracts are antioxidant with antiproliferative effect on cultured human cancer cell lines. J Evid Based Complementary Altern Med, https://doi.org/10.1155/2013/462751.

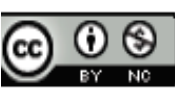

This work is licensed under a Creative Commons AttributionNon Commercial 4.0 International License.

Asian Pacific Journal of Cancer Prevention, Vol 20 